\title{
Why we need guidelines for clinical trials in vasculitis and systemic lupus erythematosus
}

\section{Chetan Mukhtyar, Dimitrios Boumpas, Caroline Gordon, Wolfgang Gross, David Jayne, Raashid Luqmani}

See linked article, p 605

$\mathrm{T}$ he systemic vasculitides and systemic lupus erythematosus (SLE) are uncommon systemic rheumatic diseases. They have attracted increasing clinical trial activity, for which there is a need for international consensus and guidelines on clinical research methodology. There have been a number of relatively small studies of these diseases. Unfortunately, these have had varying design, outcome and assessment measures, thus it is difficult to interpret the evidence or subject it to a meta-analysis, and this has resulted in considerable uncertainty-for example, in deciding the role and dosing of cyclophosphamide in vasculitis or SLE. ${ }^{1-4}$ Standardisation of the methodology for conducting clinical trials facilitates recruitment of patients into larger multicentre studies, which are likely to include nonexpert centres, because of the low incidence and prevalence of cases. There is increasing involvement by the pharmaceutical industry in clinical trials of SLE and vasculitis. These companies will also need guidelines on which to base their trial protocols. Furthermore, standardisation allows for future inter-trial comparisons and meta-analysis of separately conducted studies. The purpose of this editorial is to highlight the existence of a new set of recommendations to improve the conduct of clinical trials in vasculitis and SLE.

The vasculitis and SLE working groups of the European League Against Rheumatism (EULAR) Standing Committee on International Clinical Studies Including Therapeutic Trials (ESCISIT) have developed guidelines based on current evidence. $^{56}$ In the absence of evidence, expert consensus has formed the basis of some of the recommendations. In a review of 370 separate clinical studies of antineutrophil cytoplasmic antibody-associated systemic vasculitis (AASV) and polyarteritis nodosa, only 42 had sufficient consistency to allow comparison between trials. ${ }^{6}$ These 42 papers were analysed and form the basis for the current guidelines in vasculitis. Each guideline has been reviewed by the ESCICIT committee. The guidelines emphasise the need for collaboration and standardization of terminology and assessment in clinical trials. They also acknowledge the lack of diagnostic criteria in vasculitis and highlight the need for clear definitions of disease states (Table 1). The measurement and documentation of disease activity and diseaserelated damage should be standardised, using validated assessment tools to compare the efficacy of trial interventions or measure long-term morbidity in observational studies. This is especially important because of the absence of valid biomarkers to reflect disease activity in SLE and AASV. Standardisation of concomitant therapy with steroids or other drugs such as angiotensin-converting enzyme inhibitors and trimethoprim/sulfamethoxazole is important and is highlighted in both sets of guidelines. Many studies of vasculitis include mixed cohorts with different diagnostic subgroupings of vasculitis. Similarly, in SLE, patients may have variable organ involvement. In these circumstances, the recommendations suggest that common endpoints should be identified and that the trial is powered adequately to perform subgroup analyses. Both sets of guidelines stress the importance of long-term observation, as the likelihood of relapse in these diseases can only be appreciated over years rather than months. For example, a followup period of 5 years for a remission maintenance study in vasculitis has been recommended, where practical.

The lack of valid biomarkers in vasculitis and SLE mean that clinical assessment tools are relied upon for assessment of disease activity and damage. These clinical tools (eg Birmingham Vasculitis Activity Score (BVAS), BVAS for Wegener's granulomatosis, Vasculitis Damage Index, Systemic Lupus Erythematosus Disease Activity Index, British Isles Lupus Assessment Group Index, Systemic Lupus International Collaborating Clinics/ American College of Rheumatology Index), required trained personnel for appropriate use. With increasing recruitment of patients from non-expert centres, such training is desirable before trial recruitment is commenced. It may also be desirable that the recruitment of patients to clinical trials and their assessment should be performed by doctors rather than allied health professionals, as most nurses and physician assistants do not have sufficient experience to differentiate disease activity from other comorbidities such as infection and malignancy.

There is a need to consider pharmacoeconomic outcome measures in clinical trials, especially if biological agents are to be evaluated. The economic cost of the intervention should be balanced against the costs of treating ongoing chronic lowgrade morbidity with current (less expensive) treatments that are likely to have lower efficacy and/or greater toxicity than the new intervention. We would encourage future studies to include a pharmacoeconomic aspect so that the use of potentially expensive agents can be justified by demonstrating cost-effective improvements in disease activity, quality of life and lower toxicity. However, we recognise there is little current experience of pharmacoeconomic evaluation in these diseases.

The development of recommendations for clinical trials might be seen as limiting or as forcing a change in practice. Individual groups might perceive the guidance as a way of undermining professional autonomy by making individual

Table 1 Definitions of clinical states of ANCA-associated vasculitis used in EUVAS trials

\begin{tabular}{|c|c|}
\hline Clinical subgroup & Definition \\
\hline Localised & $\begin{array}{l}\text { Upper and/or lower respiratory tract disease without any other systemic involvement or } \\
\text { constitutional symptoms }\end{array}$ \\
\hline Early systemic & Any, without organ-threatening or life-threatening disease \\
\hline Generalised & Renal or other organ-threatening disease, serum creatinine $<500 \mu \mathrm{mol} / \mathrm{l}$ \\
\hline Severe & Renal or other vital organ failure, serum creatinine $>500 \mu \mathrm{mol} / \mathrm{l}$ \\
\hline Refractory & Progressive disease unresponsive to glucocorticoids and cyclophosphamide \\
\hline
\end{tabular}


Table 2 Examples of application of standardisation in clinical trials of vasculitis and SLE (this is not an exhaustive list).

\begin{tabular}{|c|c|c|}
\hline Recommendations & Vasculitis & SLE \\
\hline Classification: apply standard classification criteria & $\begin{array}{l}\text { Chapel Hill consensus definitions or ACR classification } \\
\text { criteria for vasculitis }^{89}\end{array}$ & ARA classification criteria for $\mathrm{SLE}^{10}$ \\
\hline $\begin{array}{l}\text { Staging/severity/eligibility: apply standardised } \\
\text { structured clinical evaluation }\end{array}$ & BVAS, BVAS/WG, DEl, VDI ${ }^{11-14}$ & BILAG Index, SLEDAI , SLICC/ACR Index ${ }^{15-17}$ \\
\hline $\begin{array}{l}\text { Outcome measures: clinical evaluation of disease } \\
\text { activity and damage, quality of life and economic } \\
\text { impact }\end{array}$ & $\begin{array}{l}\text { BVAS, BVAS/WG, DEI, VDI, SF36, QALY } \\
\text { assessment }^{11-1418}\end{array}$ & $\begin{array}{l}\text { BILAG Index, SLEDAI, SLICC/ACR Index, SF36, QALY } \\
\text { assessment }^{15-18}\end{array}$ \\
\hline $\begin{array}{l}\text { Biomarkers*: serological assessment of disease } \\
\text { Relapse/remission/refractory disease definitions: } \\
\text { based on standardised clinical evaluation and } \\
\text { qualified by use of ongoing therapy }\end{array}$ & $\begin{array}{l}\text { ANCA, CRP, renal function } \\
\text { BVAS, BVAS/WG, DEI }\end{array}$ & $\begin{array}{l}\text { dsDNA, complement, renal function } \\
\text { BILAG Index, SLEDAI }^{15} 16\end{array}$ \\
\hline Immunosuppressive therapy: standardise & $\begin{array}{l}\text { Standard or biological therapy, placebo where } \\
\text { indicated }\end{array}$ & $\begin{array}{l}\text { Standard or biological therapy, placebo where } \\
\text { indicated }\end{array}$ \\
\hline Steroid therapy: standardise & Dose and method of administration & Dose and method of administration \\
\hline Concomitant therapy: standardise & Trimethoprim/sulfamethoxazole & ACE inhibitors \\
\hline \multicolumn{3}{|c|}{$\begin{array}{l}\text { ACE, angiotensin-converting enzyme; ANCA, antineutrophil cytoplasmic antibody; ARA, American Rheumatism Association; BILAG Index, British Isles Lupus } \\
\text { Assessment Group Index; BVAS, Birmingham Vasculitis Activity Score; BVAS/WG, Birmingham Vasculitis Activity Score for Wegener's Granulomatosis; CRP, C reactive } \\
\text { protein; DEI, Disease Extent Index; dsDNA, double-stranded DNA; IV, intravenous; QALY, quality-adjusted life year; SF36, Short Form } 36 ; \text { SLE, systemic lupus } \\
\text { erythematosus; SLEDAl, Systemic Lupus Erythematosus Disease Activity Index; SLICC/ACR, Systemic Lupus International Collaborating Clinics/American College Of } \\
\text { Rheumatology; VDI, Vasculitis Damage Index. } \\
\text { "We recommend that these investigations are performed routinely as part of clinical protocol but cannot be used on their own to guide therapy unless the trial design is } \\
\text { aimed at testing the validity of these markers. }\end{array}$} \\
\hline
\end{tabular}

researchers accountable for their failure to adhere to the guidelines. ${ }^{7}$ In reality, the guidelines are meant to function as a readily available framework, which is based on a firm evidence base or widespread expert consensus, around which a clinical trial could be designed (Table 2). We recognise that many international experts will have not been involved in the formation of these guidelines, and welcome their views and any evidence-based improvements they can make to any future versions of these guidelines. There are numerous barriers to implementing any guideline, including excess paperwork and time, a lack of ownership of the individual guideline and a requirement to change established patterns of practice.

Widespread availability of the EULAR Guidelines through publication in Annals of the Rheumatic Diseases and their accompanying editorials will allow access by doctors and academics. This is an important step towards their implementation, and should assist in their subsequent improvement. Uptake of the guidelines will be vital to their development, and we would encourage all health professionals involved in caring for patients and conducting clinical trials to make use of them. It is inevitable that these guidelines will have to be modified with evolving therapies and better quality of evidence. Future trials based on these guidelines will highlight the limitations of the guidelines themselves and in turn lead to an improvement in the standard of the guidelines. We hope that researchers involved in current and future studies of systemic vasculitis and SLE will find the guidelines of use in their everyday practice.

Ann Rheum Dis 2007;66:569-570. doi: 10.1136/ard.2006.065854

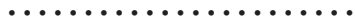

Authors' affiliations

Chetan Mukhtyar, Raashid Luqmani, Botnar Research Centre, University of Oxford, Oxford, UK

Dimitrios Boumpas, Division of Rheumatology, Clinical Immunology and Allergy, University of

Crete, Heraklion, Greece

Caroline Gordon, Department of Rheumatology,

Birmingham University, Birmingham, UK Wolfgang Gross, Department of Rheumatology, University Hospital of Schleswig-Holstein,

Campus Lubeck, Lubeck, Germany

David Jayne, Department of Nephrology,

Addenbrooke's Hospital, Cambridge, UK

Correspondence to: Dr Raashid Luqmani DM FRCP, FRCP(E), Consultant Rheumatologist/ Senior Lecturer, Rheumatology Department, Nuffield Orthopaedic Centre and University of Oxford, Windmill Road, Oxford OX3 7LD, UK; raashid.luqmani@noc.anglox.nhs.uk; raashid. luqmani@noc.anglox.nhs.uk

Accepted 6 February 2007

Competing interests: None declared.

\section{REFERENCES}

1 de Groot K, Adu D, Savage CO. The value of pulse cyclophosphamide in ANCA-associated vasculitis: meta-analysis and critical review. Nephrol Dial Transplant 2001;16:2018-27.

2 Flanc RS, Roberts MA, Strippoli GF, Chadban SJ, Kerr PG, Atkins RC. Treatment of diffuse proliferative lupus nephritis: a meta-analysis of randomized controlled trials. Am J Kidney Dis 2004:43:197-208.

3 Boumpas DT, Sidiropoulos P, Bertsias G. Optimum therapeutic approaches for lupus nephritis: what therapy and for whom? Nat Clin Pract Rheumatol 2005; 1:22-30

4 Karassa FB, Tatsioni A, loannidis JP. Design, quality, and bias in randomized controlled trials of systemic lupus erythematosus. J Rheumato/ 2003;30:979-84

5 Gordon C, Bertsias G, loannidis JP, Boumpas DT. EULAR recommendations for conducting clinical trials in SLE. Ann Rheum Dis 2006;65(Suppl 2):2.

6 Hellmich B, Flossmann O, Gross WL, Bacon P, Cohen-Tervaert JW, Guillevin L, et al. EULAR recommendations for conducting clinical studies and/ or clinical trials in systemic vasculitis: Focus on ANCA-associated vasculitis. Ann Rheum Dis 2006;
Published Online First. 14 December 2006, doi: 10.1136/ard.2006.062711

7 Timmermans S. From autonomy to accountability: the role of clinical practice guidelines in professional power. Perspect Biol Med 2005;48:490-501.

8 Jennette JC, Falk RJ, Andrassy K, Bacon PA, Churg J, Gross WL, et al. Nomenclature of systemic vasculitides. Proposal of an international consensus conference. Arthritis Rheum 1994;37:187-92.

9 Fries JF, Hunder GG, Bloch DA, Michel BA, Arend WP, Calabrese LH, et al. The American College of Rheumatology 1990 criteria for the classification of vasculitis. Summary. Arthritis Rheum 1990;33:1135-6.

10 Tan EM, Cohen AS, Fries JF, Masi AT, McShane DJ, Rothfield NF, et al. The 1982 revised criteria for the classification of systemic lupus erythematosus. Arthritis Rheum 1982;25:1271-7.

11 Exley AR, Bacon PA, Luqmani RA, Kitas GD, Gordon C Savage CO, etal. Developmentand initial validation of the Vasculitis Damage Index for the standardized clinical assessment of damage in the systemic vasculitides. Arthritis Rheum 1997:40:371-80.

12 Stone JH, Hoffman GS, Merkel PA, Min YI, Uhlfelder ML, Hellmann DB, et al. A disease-specific activity index for Wegener's granulomatosis: modification of the Birmingham Vasculitis Activity Score. International Network for the Study of the Systemic Vasculitides (INSSYS). Arthritis Rheum $2001 ; 44: 912-20$.

13 Lugmani RA, Bacon PA, Moots RJ, Janssen BA, Pall A, Emery $P$, et al. Birmingham Vasculitis Activity Score (BVAS) in systemic necrotizing vasculitis. QJM 1994;87:671-8.

14 de Groot K, Gross WL, Herlyn K, Reinhold-Keller E. Development and validation of a disease extent index for Wegener's granulomatosis. Clin Nephrol 2001;55:31-8.

15 Hay EM, Bacon PA, Gordon C, Isenberg DA, Maddison P, Snaith ML, et al. The BILAG index: a reliable and valid instrument for measuring clinical disease activity in systemic lupus erythematosus. Q J Med 1993:86:447-58.

16 Bombardier C, Gladman DD, Urowitz MB, Caron D, Chang $\mathrm{CH}$. Derivation of the SLEDAI. A disease activity index for lupus patients. The Committee on Prognosis Studies in SLE. Arthritis Rheum 1992;35:630-40.

17 Gladman DD, Goldsmith CH, Urowitz MB, Bacon P, Fortin P, Ginzler E, et al. The Systemic Lupus International Collaborating Clinics/American College of Rheumatology (SLICC/ACR) Damage Index for Systemic Lupus Erythematosus International Comparison. J Rheumatol 2000;27:373-6.

18 Ware JE Jr, Sherbourne CD. The MOS 36-item short-form health survey (SF-36). I. Conceptual framework and item selection. Med Care 1992;30:473-83. 